\title{
Intravaginal testicular torsion in newborns. To fix or not to fix the contralateral testis?
}

\author{
La torsione testicolare intravaginale nel neonato. E' necessario fissare il testicolo controlaterale? \\ G. Bordin, ${ }^{1}$ F. Parolini, ${ }^{1}$ A. Morandi, ${ }^{1}$ G. Farris,${ }^{1}$ E. Leva, ${ }^{1}$ M. Torricelli ${ }^{1}$
}

Key words: intravaginal torsion, newborn, orchiopexy, testicular torsion

\begin{abstract}
scrotal swelling suggesting testicular torsion is a rare urological emergency which requires a clinical urgent evaluation and most of the times must be managed surgically. In newborns it can occur in the postnatal period, usually within the twenty-eighth day of life, or more frequently in utero, during the descent of the testis into the scrotum. Usually its poor fixedness allows the testis an abnormal mobility inside the scrotum, configuring the framework of extravaginal torsion. On the contrary during the perinatal period a twist that takes place inside the tunica vaginalis, known as intravaginal torsion, is extremely uncommon and only few cases are well documented in the literature. Authors present a rare case of intravaginal testicular torsion occurred in perinatal period. In this situation only the early surgical exploration of the scrotum may allow the rescue of the gonad, although in rare cases. Timing of surgical treatment and need for contralateral testicular fixation remain controversial. However since the anatomical defect of the tunica vaginalis can be bilateral the surgical fixation even of the contralateral testis is important, now or later, in order to prevent any future torsion of this gonad. The authors also present a brief review of recent literature on the subject.
\end{abstract}

Department of Pediatric Surgery, Padiglione Alfieri, FONDAZIONE IRCCS CA' GRANDA - Ospedale Maggiore Policlinico Milano. Via F. Sforza 28, 20122

Indirizzo per la corrispondenza (Corresponding author):

Department of Pediatric Surgery, Padiglione Alfieri,

FONDAZIONE IRCCS CA' GRANDA

Ospedale Maggiore Policlinico Milano. Via F. Sforza 28, 20122.

Phone: 00390255032544

Fax: 00390255036570

E-mail: articles.chped@gmail.com

\section{Riassunto}

Nel neonato la comparsa di tumefazione scrotale improvvisa suggerisce la diagnosi di torsione testicolare; essa costituisce una rara ma temibile urgenza urologica e richiede una pronta valutazione clinica in vista di una possibile condotta chirurgica d'emergenza per preservare la vitalità testicolare. Nel neonato la torsione può avvenire nel periodo postnatale, generalmente entro il ventottesimo giorno di vita, o più frequentemente in utero durante la discesa del testicolo nello scroto. Solitamente la lassità dei supporti anatomici permette al testicolo un'anomala mobilità all'interno dello scroto, potendo pertanto esporre al rischio che si realizzi una torsione extravaginale. In questa epoca al contrario una torsione che avviene all'interno della tonaca vaginale, ovvero intravaginale, è estremamente rara e solo pochissimi casi sono ben documentati in letteratura. Gli Autori presentano un raro caso di torsione testicolare intravaginale occorsa nel periodo perinatale. In questa situazione solo l'esplorazione chirurgica precoce dello scroto può consentire, seppur in rari casi, il salvataggio della gonade. Questo timing di intervento e la necessità di fissazione del testicolo controlaterale rimangono ancora controversi. Tuttavia, poiché il difetto anatomico di impianto anomalo della tonaca vaginale può essere bilaterale, è importante la fissazione chirurgica, immediata o successiva, anche del testicolo controlaterale, per prevenire un'eventuale futura torsione di quella gonade. Gli Autori presentano inoltre una breve revisione della letteratura più recente sull'argomento.

\section{Introduction}

Testicular torsion represents a rare cause of acute scrotum in the newborn: only a prompt clinical and surgical evaluation can allow the rescue of the testis. ${ }^{1}$ The twist may occur in the uterus, usually during testicular descent into the scrotum, or in the perinatal period, and in most of the cases is due to an incomplete attachment of the tunica vaginalis to the scrotal wall, a condition called "extravaginal". Contrariwise the intravaginal torsion, typical of prepuberal 


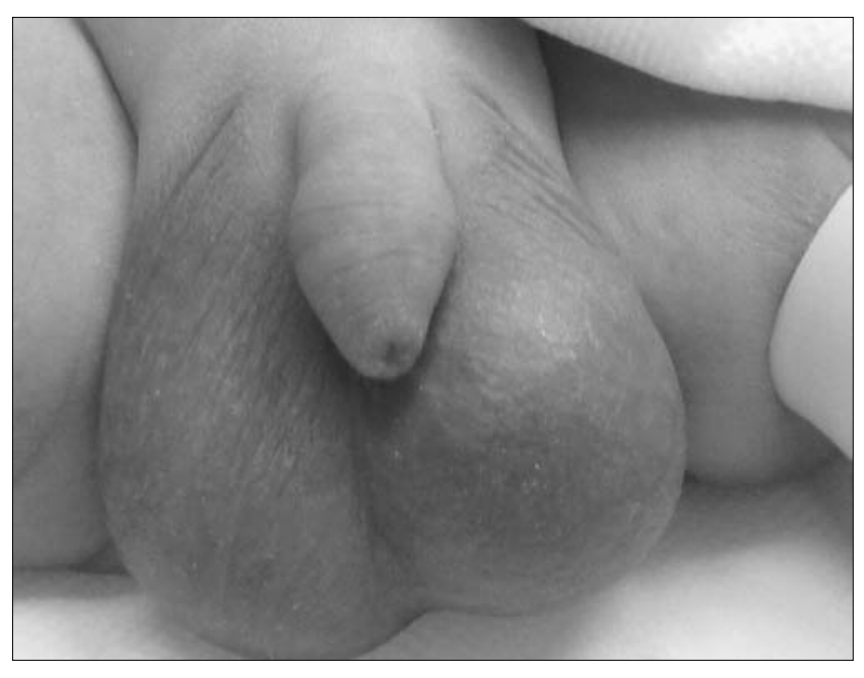

Figure 1.

Left emiscrotum swelling

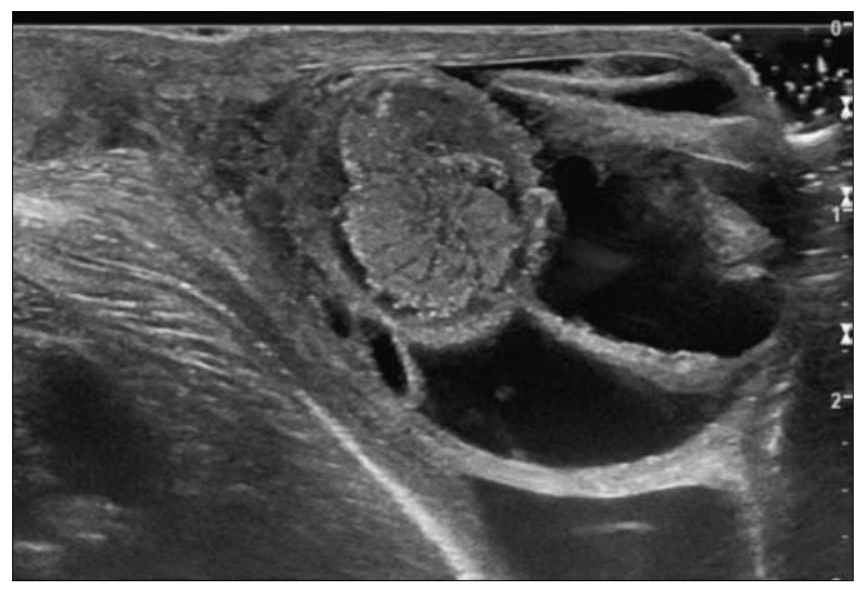

Figure 2.

Left testis US showing testicular wall thickening and an important layer of hydrocele with fibrin branches in a radial pattern.

age, is extremely rare in newborns. In these infants the management, the timing of surgery and the need for contralateral testicular fixation remain controversial. The Authors present a rare case of a neonatal intravaginal torsion.

\section{Case report}

An otherwise healthy male newborn, born at term, was brought to our attention for a swelling of the left emiscrotum (Figure 1). The prenatal ultrasound examinations were normal. At birth a painful and swelling left emiscrotum was found: the left testicle appeared hard in consistency and size increased, covered by hyperemic skin; transillumination was positive for the presence of fluid. The cremasteric reflex was completely abolished on the left and well preserved on the right. The right emiscrotum was normal. An abdominal ultrasound, without detection of pathologic findings, and a testicular ultrasound were therefore performed. Tumor markers were also requested; all resulted normal. At ultrasound the left testicular wall was thickened and an important layer of hydrocele with fibrin branches arranged in a radial pattern was evident (Figure 2). Doppler ultrasound revealed a significant reduction in vascularization. The sonographic findings of the right testicle were normal. The baby underwent early surgical exploration through a left transscrotal access, and the framework of an intravaginal torsion of the testis was evident. The section of the tunica vaginalis revealed abundant branches of fibrin inside and an increased size and consistency of the testis, with necrotic aspects (Figure 3). Left orchiectomy was performed, while right emiscrotum, on account of its clinical and imaging normality, was not explored. On subsequent follow-up the baby did not present any problem; fixation of the contralateral testis was successfully performed one year later.

\section{Discussion}

Perinatal testicular torsion represents a rare event and many controversies about the clinical presentation and the surgical management are still present. ${ }^{2}$ Perinatal torsion can be divided into two subgroups: prenatal $(72 \%)$ and postnatal torsion (28\%), which usually occurs within the first 30 days of life. ${ }^{3}$ The twisting of the spermatic cord is generally due to an incomplete attachment of the tunica vaginalis to the scrotal wall and it is defined "extravaginal", while intravaginal torsion seems to be a typical phenomenon of the puberty. The circumstances favoring intravaginal torsion are usually represented by congenital anatomical abnormalities such as excessive laxity of gubernaculum testis and an high attachment of the tunica vaginalis to the spermatic cord, conditions known as "bell clapper deformity". ${ }^{4}$ This deformity has been documented in prepuberal children, while in literature only few cases have been described in neonates. ${ }^{5}$ Neonatal testicular torsion has an extremely tricky presentation and sometimes may remain completely asymptomatic. Both the antenatal and postnatal ultrasounds often do not provide specific indicators of early testicular torsion. In particular, the testicular alterations are clearly visualized on ultrasound only few hours later. ${ }^{4}$ In differential diagnosis diseases such as cancer, incarcerated hernia, meconium peritonitis, idiopathic testicular infarction and scrotal hematoma secondary to adrenal hemorrhage should be considered. ${ }^{6}$ The correct timing to save the testicle, prevention of its future twist and especially the prevention of contralateral testicular torsion are still discussed. ${ }^{7}$ In prenatal torsion the possibility to save the testicle is usually none and orchiectomy is generally performed. However some Authors suggest early surgical approach, to save the slightest percentage of testes not yet in necrosis. Others believe that it is preferable to confirm the diagnosis by imaging and postpone the surgery, so reducing the surgical and anesthesiological risks of the newborn. ${ }^{8}$ The twist generally hesitates in testicular necrosis and a more precocious surgical treatment would not however allow to save the testicle. The savable testicles would generally be those twisted in the postnatal period. In these cases early surgical approach is undoubtedly justified ${ }^{9}$ and represents the only mean available to confirm the diagnosis and to save a still functional testis. When the 


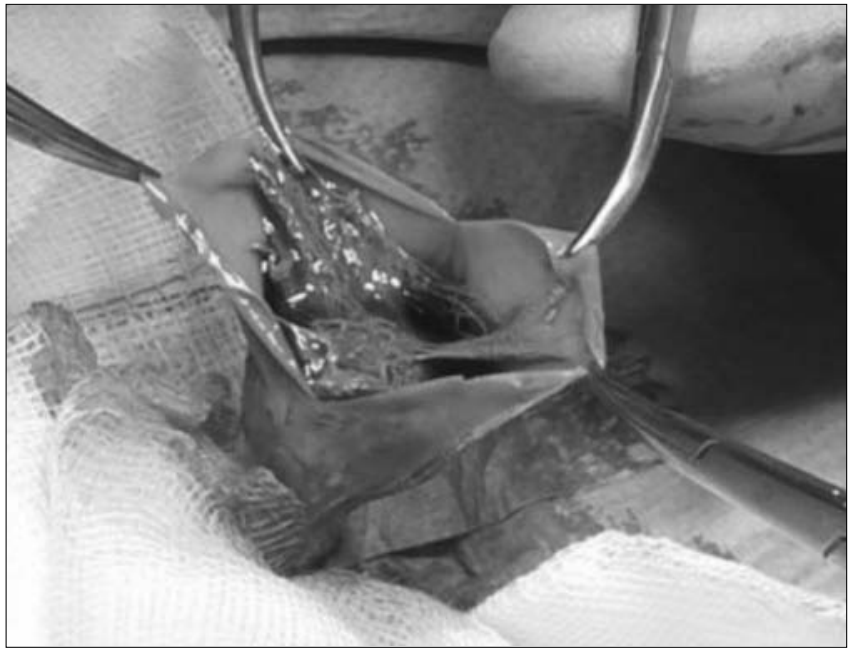

Figure 3.

Intraoperative picture showing intravaginal testicular torsion when opening the tunica vaginalis, with abundant branches of fibrin inside tunica vaginalis and necrotic aspects of the testis.

testis is vital its fixation is indicated. Otherwise indications to orchiectomy depend largely on the macroscopic characteristics and the period between the onset of symptoms and detorsion. The need of a contralateral orchiopexy and the best time for its eventual execution are also controversial. The proposed strategies include the non-execution of contralateral surgery, the orchiopexy during scrotal emergency exploration ${ }^{7}$ and the interval orchiopexy. ${ }^{9}$ Most of the recent literature recommends early bilateral scrotal exploration and orchiopexy. ${ }^{10}$ The rational for the execution of the contralateral fixation is to avoid a contralaterally twist. The risk of bilateral torsion is present both in the context of neonatal extravaginal and intravaginal, where, however, this risk is even greater. In fact, the anatomic abnormality that predisposes to intravaginal torsion is often present bilaterally, thus involving the risk that the twist of the contralateral gonad occurs in stages of life not limited to the neonatal period. The orchiopexy can well be performed at the same surgical exploration or, alternatively, as in elective timing, in order to reduce the aesthesiological and surgical risks of the neonatal period. Intravaginal testicular torsion in newborns represents a rare event that can have serious consequences in terms of testicular vitality. When the twist occurs in the postnatal period only emergency surgery can allow the rescue of the testis. When the torsion occurs in uterus testicular necrosis is rather the rule, and the timing of surgery remains controversial. According to the most recent literature, the Authors still favor early surgical exploration, even in the unlikely possibility that the testicle could be spared. The fixing of the contralateral testis at a later time seems a reasonable option, in order to minimize anesthesiological and surgical risk of the neonatal period.

\section{References}

1 Brandt MT, Sheldon CA, Wacksman J, Matthews P. Prenatal testicular torsion: principles of management. J Urol 1992;147(3):670-2.

2 Ahmed SJ, Kaplan GW, DeCambre ME. Perinatal testicular torsion: preoperative radiological findings and the argument for urgent surgical exploration. J Pediatr Surg 2008; 43:1563-5.

3 Nariman S, Khaleghnejad-Tabari A. Perinatal testicular torsion: a case report. Arch Iran Med 2005; 8:321-2.

4 Fabrizi G, Signoretti P. Torsione del testicolo e degli annessi testicolari. In: Domini R, Belbusti F, Lima M, Signoretti P, Jasonni V, editors. Argomenti di Andrologia chirurgica pediatrica con applicazioni di tecniche microchirugiche. Piccin Nuova Libreria, Padova 1991. p. 165-178.

5 Van Glabeke E, Philippe-Chomette P, Gall O, Oro H, Larroquet M, Audry G. Spermatic cord torsion in the newborn: role of surgical exploration. Arch Pediatr 2000; 7:1072-6.

6 Favorito LA, Cavalcante AG, Costa WS. Anatomic aspects of epididymis and tunica vaginalis in patients with testicular torsion. Int Braz J Urol 2004; 30:420-4.

7 Rhodes HL, Corbett HJ, Horwood JF, Losty PD. Neonatal testicular torsion: a survey of current practice amongst paediatric surgeons and urologists in the United Kingdom and Ireland. J Pediatr Surg. 2011;46(11):2157-60.

8 Tiret L, Nivoche Y, Hatton F, Desmonts JM. Complications related to anesthesia in infants and children. A prospective survey of 40240 anaesthetics. Br J Anaesth 1988; 61:263-9.

9 Djahangirian O, Ouimet A, Saint-Vil D. Timing and surgical management of neonatal testicular torsions. Journal of Pediatric Surgery 2010; 45;1012-1015.

10 Guerra LA, Wiesenthal J, Pike J, Leonard MP. Management of neonatal testicular torsion: which way to turn? CUAJ 2008; 2(4):376-9. 